\title{
Recommendations of Optimal Sampling Rates for Periodic Output Feedback Based Discrete Mode PSS
}

\author{
Mahendra Bhadu \\ *Assistant Professor, Govt. Engineering College Bikaner, Rajasthan, India. \\ Corresponding Author: mbhadu@gmail.com
}

\begin{abstract}
In this paper, an attempt is made to recommend the optimal sampling time period for Periodic Output Feedback (POF) based discrete mode power system stabilizer (DPSS). Various collection of input and output sampling time interval has been used in the designing of POF based DPSS. The Particle Swarm Optimization (PSO) technique is used to obtain the optimal gain matrix of the POF controller as well as the optimal sampling time intervals. The effectiveness of POF based DPSS over continuous mode lead-lag PSS is certified using small-signal stability studies. The parameters of lead-lag type continuous mode PSS is also tuned using the PSO technique. The PSS is designed using POF technique for single machine infinite bus (SMIB) system, considering a variety of sampling time intervals at input-output port. Finally, a trial is made to propose an optimum input and output sampling time period for SMIB test power system, through simulation studies.
\end{abstract}

Keywords:Multi-rate output feedback; Periodic output feedback; Optimal sampling rate; Power system stabilizer; Discrete controller.

\section{INTRODUCTION}

The large-scale interconnected power systems are subjected to continuous disruption due to the presence of unforeseen load disturbances, parameter uncertainties, and faults. Due to the occurrence of disturbance in the complex power system, the electromechanical oscillations will be encountered among the generators. For the safe procedure and to preserve the power transmission capability of complete power systems, the emerging oscillations need to be damped out quickly. The electromechanical oscillations are characterized by different modes. The local mode of oscillation is encountered in a single plant or a single generator, usually varies in the range of 0.7 to $2.0 \mathrm{~Hz}$. The power system stabilizer is an important tool to damp out these electromechanical oscillations (Kundur et al., 1989 \& Klein et al., 1991). lubricants and mechanical distortion may occur due to temperature rise (Jebaseeli. 2015).

The stablizer and Automatic Voltage Regulator (AVR) is situated at the power plant itself. The conventional stablizer i.e. $\Delta \omega$-PSS is designed using well-established methods like residue method. The PSS that gets its signal from the generator itself normally termed as local PSS. Most of the work related to PSS designing was done in continuous mode. But in the modern era, due to the increasing tendency of discrete sensors, the system variables like speed, voltage, current, power, etc. are being measured and processed in the discrete domain(Bhattacharya et al., 1995, Park et al., 1996, Kothari et al., 1993 \& Lee et al., 1981).

In addition to the conventional lead-lag controller, optimal control techniques are also used to design the controllers, to be used for a modern power system. The optimal control methods employ the state space representation of the given test model. State feedback control technique is employed to calculate the gain matrix, that in turn, is used in the given power system model. The dynamic output feedback approach is adopted for designing 
a PSS but with the increment of the order of the feedback system (Rao et al., 2000 \& Gupta et al., 2005). In the Multirate Output Feedback(MOF) control system, the sampling of control input and sensor output is considered at various rates. If the system input is sampled at a faster pace, as compared to system output, it is described as Periodic Output Feedback(POF) (Chammas et al., 1979, Priya et al., 2012 \& Bandyopadhyay et al., 2005). However, for the controllable and observable plant, the pole placement issue may be dealt with the time-varying POF method, as shown by (Chammas et al., 1979). Recently (Gupta et al., 2005), an appreciable work has been performed to design the local-PSS in power systems using the POF techniques. However, up to the knowledge of author, an optimal sampling rate for the POF technique based controller has not recommended and implemented yet in modern power systems.

The scope of this work is to design a discrete mode local PSS in a systematic way using the concept of periodic output feedback(POF) technique, to damp out the electromechanical oscillations. After the implementation of the POF controller as a PSS, input and output optimal sampling time period has been recommended for single machine power system. The PSO technique has been used for calculating the optimum value of the gain matrix in POF controller. However, the rest of the system except the controller is in continuous mode. Finally, a comparison of classical PSS with POF based discrete mode PSS is also presented. The parameters of continuous mode lead-lag based PSS were also tuned with the help of the PSO technique.

The remaining part of the paper is formulated as follows. The basic theoretical background of POF control is mentioned in section 2. In section 3, a concise introduction of PSO and corresponding objective function formulation for SMIB power systems have been discussed. The case study of SMIB power system is described in section 4, that incorporates the systematic procedure of POF controller design and a brief outline of the test power system. Section 5 displays the results and corresponding discussions. The calculation of eigenvalue analysis of both continuous and discrete domains is mentioned in section 6 . Lastly, the conclusions drawn from the analysis of results and discussions are given in section 7 .

\section{BACKGROUND OF PERIODIC OUTPUT FEEDBACK (POF) CONTROL}

Let us consider the state-space model of nth order linear continuous time invariant power system as:

$$
\begin{aligned}
& x=A x+B u \\
& y=C x
\end{aligned}
$$

The continuous time system mentioned in (1) can be converted into a discrete time invariant system with sampling time interval $\tau$ sec as:

$$
\begin{aligned}
\mathrm{x}((\mathrm{k}+1) \tau) & =\varnothing_{\tau} \mathrm{x}(\mathrm{k})+\Gamma_{\tau} \mathrm{u}(\mathrm{k}) \\
\mathrm{y}(\mathrm{k}) & =\mathrm{C} \mathrm{x}(\mathrm{k})
\end{aligned}
$$

Now let the original continuous time system given in (1) is resample at $\Delta$ sec, considering $\mathrm{N}$ as an integer, that is $\nabla \geq$ the controllability index of given system, where the $\Delta=\tau / \mathrm{N}$ The system (1) when sampled at $\Delta$ sec is represented as:

$$
\begin{aligned}
\mathrm{x}(\mathrm{k}+1) & =\bigotimes \mathrm{x}(\mathrm{k})+\Gamma \mathrm{u}(\mathrm{k}) \\
\mathrm{y}(\mathrm{k}) & =\mathrm{C} \mathrm{x}(\mathrm{k})
\end{aligned}
$$


Here, $\varnothing_{\tau}, \Gamma_{\tau}, \mathrm{C}, \varnothing$ and $\Gamma$ are considered as constant matrices of pertinent dimensions along-with $\mathrm{x} \varepsilon \mathrm{R}^{\mathrm{n}}, \mathrm{u}$ $\varepsilon \mathrm{Rn}$, and $\mathrm{y} \varepsilon \mathrm{R}^{\mathrm{n}}$. The output is assumed to be sampled at $\mathrm{t}=\mathrm{k} \tau$, where $\mathrm{k}=0,1,2, \ldots$. The $\Gamma$ is divided into $\mathrm{N}$ subinterval of length $\Delta=\tau / \mathrm{N}$. Hence, corresponding control law is formulated as:

$$
\begin{gathered}
\mathrm{u}(\mathrm{t})=\mathrm{K}_{-}(\mathrm{l}) \mathrm{y}(\mathrm{k} \tau), \\
\mathrm{k} \tau+\mathrm{l} \Delta \leq \mathrm{t}<\mathrm{k} \tau+(\mathrm{l}+1) \Delta, \\
\mathrm{K}_{\mathrm{l+N}}=\mathrm{K}_{1}, \text { for } \mathrm{l}=0,1, \ldots, \mathrm{N}_{1} .
\end{gathered}
$$

The $\mathrm{K}(\mathrm{t})$ for $0 \leq \mathrm{t}<\tau$ is generated as piecewise constant in nature, when string $\{\mathrm{K} 0, \mathrm{~K} 1, \ldots \mathrm{KN}-1\}$ are placed in (4). The cinematic model of POF control law is depicted in Figure 1. Here it is presumed that $\left(\varnothing_{-} \tau, C\right)$ is observable and $(\varnothing, \Gamma)$ is controllable with controllability index $v$ such that $N \geq v$ (Priya et al., 2012, Bandyopadhyay et al., 2005, \& Patre et al., 1998).

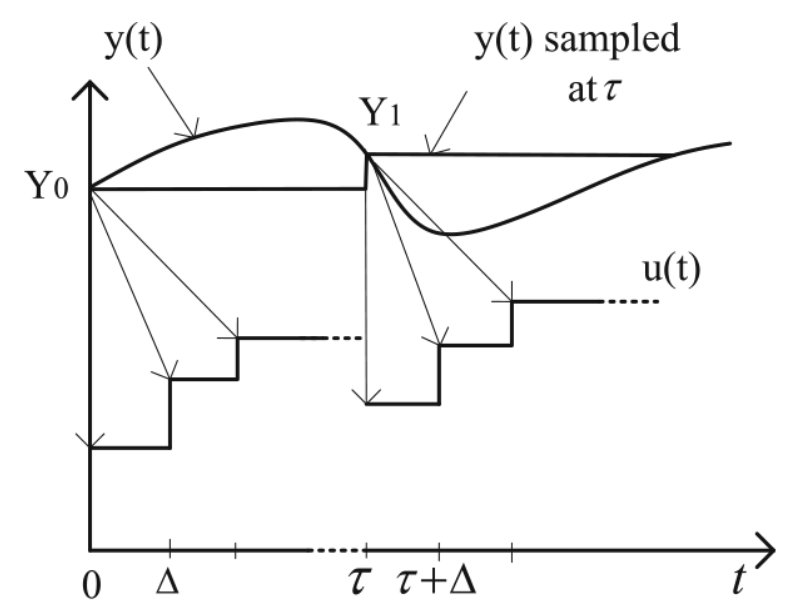

Figure 1. Photographic depiction of the POF control law

Further, defining

$$
\mathbf{K}=\left[\begin{array}{c}
\mathbf{K} 0 \\
\mathbf{K} 1 \\
\cdot \\
\cdot \\
\cdot \\
\mathbf{K N}-1
\end{array}\right] ; \mathbf{u}(\mathbf{k \tau})=\mathbf{K y}(\mathbf{k \tau})=\left[\begin{array}{c}
(\mathbf{u}(\mathbf{k \tau}) \\
\mathbf{u}(\mathbf{k \tau}+\Delta) \\
\cdot \\
\cdot \\
. @ \\
\mathbf{u}(\mathbf{k} \tau+\tau-\Delta)
\end{array}\right]
$$

Let the equation (4) is implemented into (3), implies:

$$
\mathrm{x}((\mathrm{k}+1) \tau)=\varnothing \mathrm{x}(\mathrm{k} \tau)+\Gamma \mathrm{K} \mathrm{y}(\mathrm{k} \tau)
$$

and after application of equation (5), it turns out as given in (7):

$$
\mathrm{x}((\mathrm{k}+1) \tau)=(\varnothing+\Gamma \mathrm{K} \mathrm{C}) \mathrm{x}(\mathrm{k} \tau)
$$


Similarly applying control law to system (2), it gives:

$$
x((k+1) \tau)=\varnothing^{N} x(k \tau)+\bar{\Gamma} u(k \tau)
$$

and as a result, the system (2) turns as,

$$
\mathrm{x}((\mathrm{k}+1) \tau)=\left(\varnothing^{\mathrm{N}}+\overline{\boldsymbol{\Gamma}} \overline{\mathbf{K}} \mathrm{C}\right) \mathrm{x}(\mathrm{k} \tau)
$$

Where $\Gamma^{-}=\left[\varnothing^{\wedge}(\mathrm{N}-1) \Gamma, \ldots, \Gamma\right]$.

Now, let the output injection matrix $\mathrm{G}$ is considered in such a way that

$$
\varrho\left(\varnothing^{\mathrm{N}}+\mathrm{G} C\right)<1
$$

where $\varrho()$ stand for the spectral radius.

Thus, the POF gain matrix $\mathrm{K}$ comes out as:

$$
\overline{\mathbf{\Gamma}} \overline{\mathbf{K}}=\mathrm{G}
$$

The dual of $\tau$ system is created as:

$$
\begin{aligned}
& \mathrm{x}((\mathrm{k}+1) \tau)=\varnothing \tau^{\mathrm{T}} \mathrm{x}(\mathrm{k})+\mathrm{C}^{\mathrm{T}} \mathrm{u}(\mathrm{k}) \\
& \mathrm{y}(\mathrm{k})=\Gamma_{\tau}^{\mathrm{T}} \mathrm{x}(\mathrm{k})
\end{aligned}
$$

then $\left\|\varnothing_{\tau}{ }^{\mathrm{T}}+\mathrm{C}^{\mathrm{T}} \mathrm{G}^{\mathrm{T}}\right\|<1$, hence it can also be expressed as:

$$
\|\varnothing \tau+\mathrm{GC}\|<1 .
$$

Thus, the output injection gain matrix $\mathrm{G}$ can be determined using the concept of pole placement technique. Hence, after the calculation of matrix G, the value of the POF gain matrix (K) also can be obtained. The optimum K can be calculated using the concept of the optimum location of poles. The PSO method is applied to find out the optimal location of poles

The performance evaluation of POF based discrete mode PSS is done by the eigenvalue analysis of the complete system model. For evaluation, the discrete domain poles are converted into a corresponding continuous domain. Using (14), discrete eigenvalues are determined for the given test model. The connection between continuous s-domain and corresponding z-domain can be shown as per (15), for calculation of continuous mode eigenvalues from discrete one. Hence, the eigenvalues in continuous domain can be obtained for prescribed sampling time interval, using the simplified equation (16).

$$
\begin{aligned}
& \lambda_{\text {discrete }}=\operatorname{eig}\left(\varnothing^{\mathrm{N}}+\Gamma \mathrm{KC}\right) \\
& \mathrm{z}=\mathrm{e}^{\mathrm{sT}} \\
& \lambda_{\text {conti. }}=\frac{1}{\mathrm{~T}} \log _{\mathrm{n}} \lambda_{\text {discrete }}
\end{aligned}
$$

The $\mathrm{i}^{\text {th }}$ eigen value alongwith corresponding damping factor is expressed as per given in equation (17) and (18) respectively.

$$
\begin{aligned}
& \lambda_{\mathrm{i}}=\alpha_{\mathrm{i}} \pm \mathrm{j} \beta_{\mathrm{i}} \\
& \xi_{\mathrm{i}}=-\frac{\alpha \mathrm{i}}{\left.\sqrt{\left(\alpha_{\mathrm{i}}^{2}\right)}+\beta_{\mathrm{i}}^{2}\right)} \\
& \xi_{\mathrm{i}}>\xi_{\text {min }}
\end{aligned}
$$


In this paper, the only set of POF gain matrix K is selected which satisfies the equation (19). Here, the $\xi \mathrm{min}$ is considered as the damping factor of the test system without having any controller. In addition to this, the PSO method is adopted to obtain the optimal $\mathrm{K}$ among the set of the $\mathrm{K}$ matrices which already satisfied equation (19) (Werner et al., 1995, Gupta et al., 2003, \& Bhadu et al., 2016).

\section{PARTICLE SWARM OPTIMIZATION (PSO)}

The PSO technique simulates the evolutionary process of nature and displays the outstanding characteristic in solving optimization problems, using random search algorithm. Nonetheless, the exhaustive philosophy and analysis can be seen in (Kennedy et al., 1995, Abido et al., 2002, Abd-Elazim et al., 2013 \& Eslami et al., 2012).

\subsection{SMIB system}

The position of poles required to be optimized for SMIB system, to attain the optimal K.

The equation (20) shows the objective function $\mathrm{J}$ in terms of $\Delta \omega$, to be optimized.

$$
\mathrm{J}=\sqrt{\Sigma_{\mathrm{E}_{\mathrm{is}} \mathrm{Ts}}\left(\Delta \omega_{\mathrm{i}}^{2}\right)}
$$

Here, $\Delta \omega$ represents the speed deviation of machine.

To obtain the optimum performance of system, the $\Delta \omega$ is castigated accordingly, with the constraint of location of poles within unit circle

\section{CASE STUDY}

\subsection{Single machine system}

The Heffron-Phillip model of an alternator geared with the POF controller is depicted in Figure 2. The value of the constants K1-K6 relies on the operating condition and concern machine parameters. These constants are retrieved using the small perturbation analysis of the generator modelling equation (Sauer et al., 1998 \& Heffron et al., 1952). The state-space representation of a SMIB system, without having POF controller, can be obtained using the K1-K6 model, as mentioned in (Gupta et al., 2003).

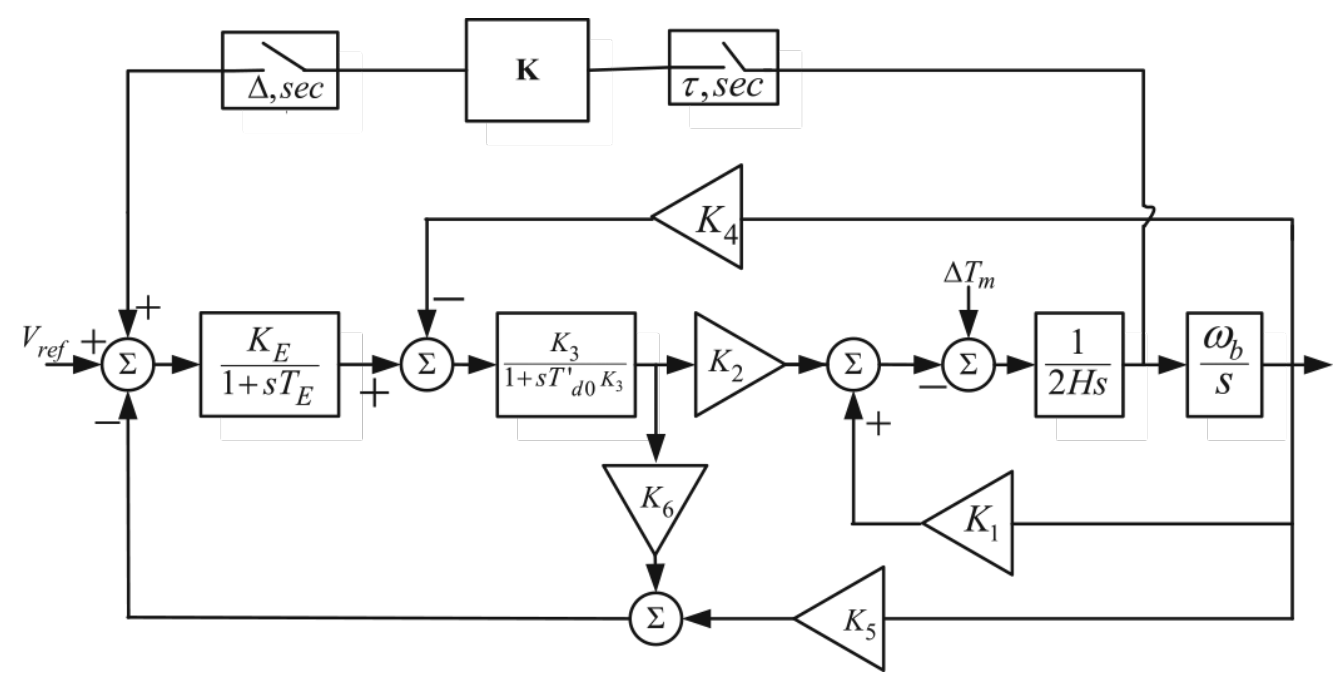

Figure 2. SMIB system with POF controller 


\subsubsection{The POF controller design steps}

The proposed POF controller design procedure is stepwise summed up here:

1) Simulate the SMIB system model without using any POF controller, and find corresponding state-space representation of model.

2) Obtain the discrete domain model from the corresponding continuous one, for appropriate sampling time intervals.

3) Calculate the $G$ with the help of pole placement method, considering the constraints.

4) Evaluate the $\Gamma^{-}$and using equation (11), evaluate corresponding gain matrix K.

5) Substitute the value of K into model and evaluate the optimized value of objective function J using PSO method.

6) For unsatisfactory case, if any, go to step 3 again else save results and adopt the similar steps for upcoming $\tau$ and $\Delta$ sets.

\section{RESULTS AND DISCUSSIONS}

For SMIB system, 3 distinct sets of $\Delta(0.005,0.0125$ and $0.025 \mathrm{sec})$ have been considered. Corresponding to the each set of $\Delta$, the $\tau$ is varied and optimized objective function is obtained.

\subsection{SMIB System}

For SMIB system, optimum $\mathrm{J}$ is shown in the Table 1, corresponding to different $\Delta$ 's. The comparison of $\mathrm{J}$ values w.r.t $\tau$, for considered $\Delta$ sets, is shown in Figure 3.

Table 1. J corresponding to different set of $\Delta$

\begin{tabular}{|c|c|c|c|c|c|c|c|c|}
\hline \multicolumn{2}{|c|}{ J corresponding to $\Delta=0.005 \mathrm{sec}$} & \multicolumn{3}{|c|}{ J corresponding to $\Delta=0.0125 \mathrm{sec}$} & \multicolumn{3}{|c|}{ J corresponding to $\Delta=0.025 \mathrm{sec}$} \\
\hline $\mathbf{N}$ & $\boldsymbol{\tau}(\mathbf{s e c})$ & $\mathbf{J}$ & $\mathbf{N}$ & $\boldsymbol{\tau}(\mathbf{s e c})$ & $\mathbf{J}$ & $\mathbf{N}$ & $\boldsymbol{\tau}(\mathbf{s e c})$ & $\mathbf{J}$ \\
\hline 5 & 0.025 & 149.6 & 2 & 0.025 & 93.89 & 2 & 0.05 & 33.87 \\
\hline 8 & 0.04 & 96.74 & 3 & 0.0375 & 100.88 & 3 & 0.075 & 16.92 \\
\hline 10 & 0.05 & 31.89 & 4 & 0.05 & 46.17 & 4 & 0.1 & 17.13 \\
\hline 12 & 0.06 & 16.96 & 5 & 0.0625 & 16.98 & 7 & 0.175 & 42.98 \\
\hline 13 & 0.065 & 64.98 & 7 & 0.0875 & 78.01 & 8 & 0.2 & 44.01 \\
\hline 15 & 0.075 & 96.97 & 8 & 0.1 & 90.21 & 10 & 0.25 & 45.88 \\
\hline
\end{tabular}




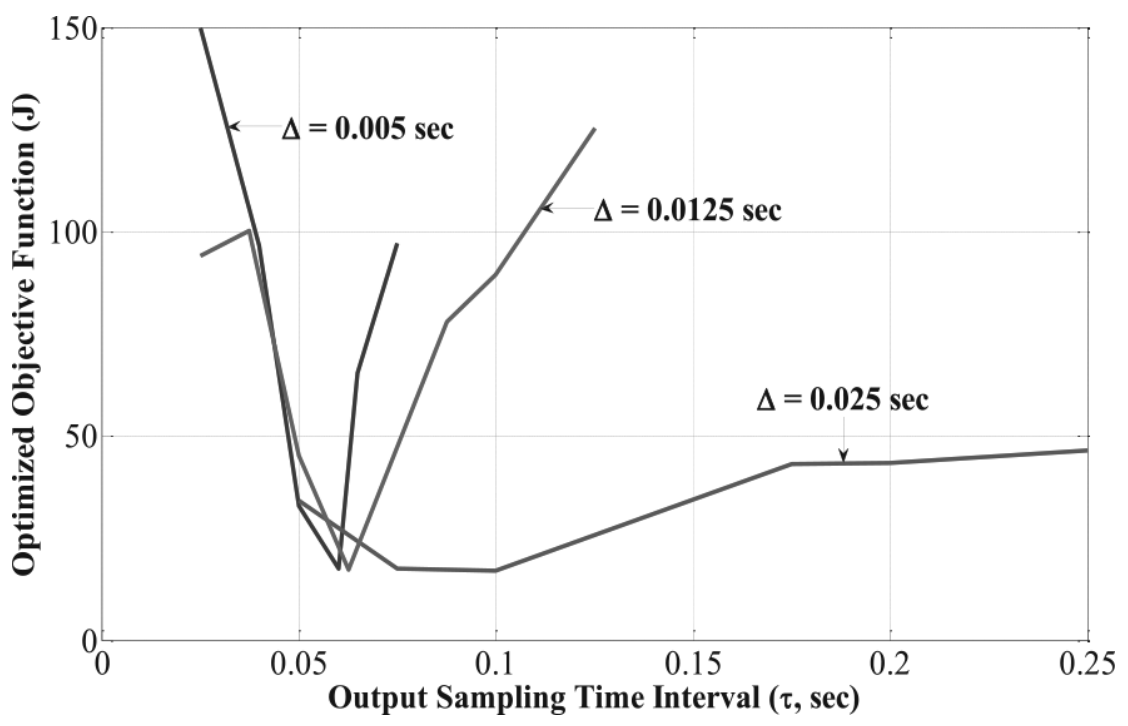

Figure 3. Optimized Js for three different sets of $\Delta$ for SMIB system

The speed deviation of machine is compared for proposed POF based PSS with classical lead-lag PSS, as shown in figure 4.

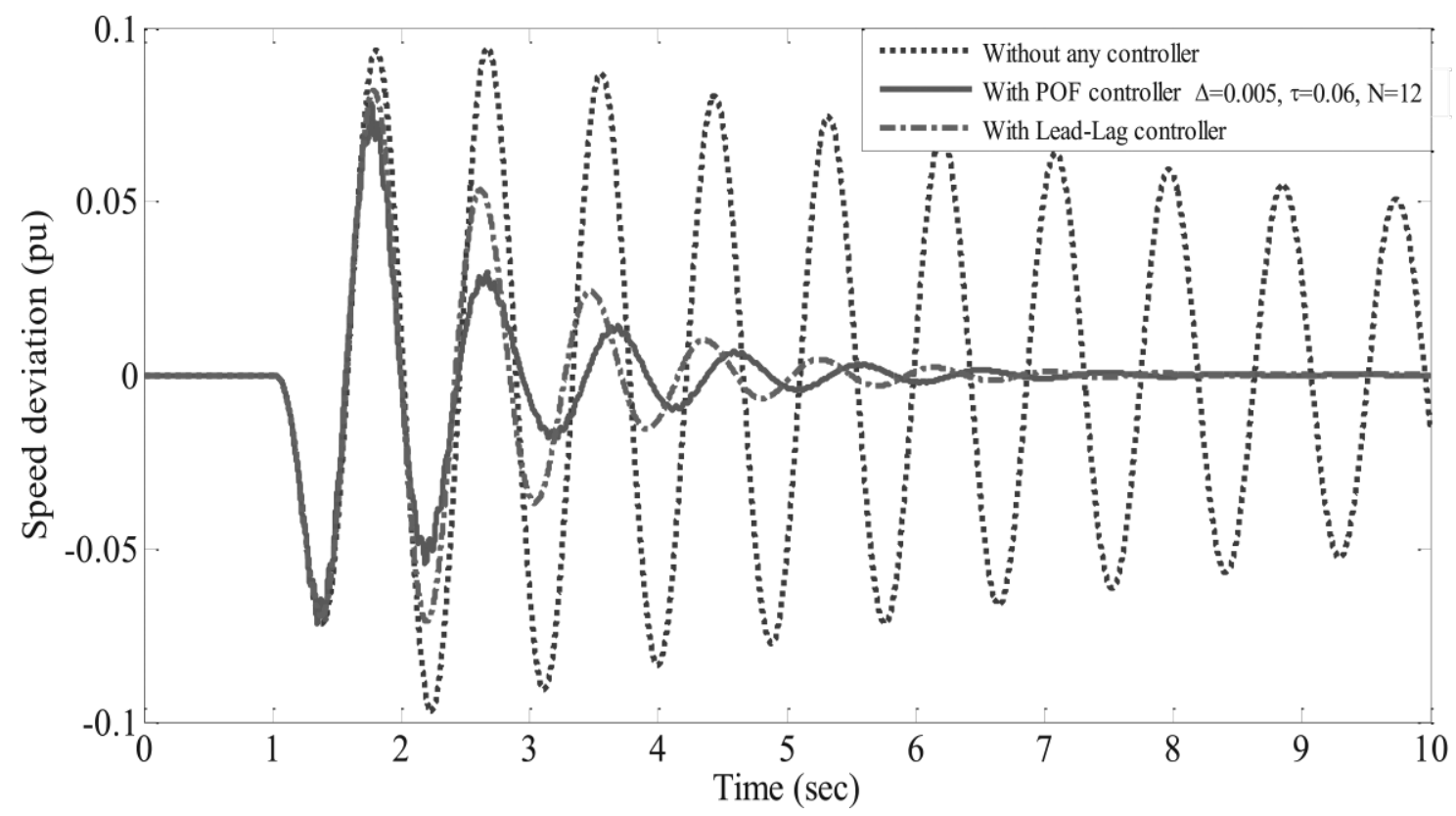

Figure 4. Speed deviation comparison with POF based DPSS and classical PSS

Table 2 represents the summary of optimum J corresponding to each $\Delta$ set, with $\mathrm{K}$ matrices. 
Table 2. Optimum value of J and corresponding K

\begin{tabular}{|c|c|c|c|l|}
\hline $\mathbf{N}$ & $\boldsymbol{\Delta}$ & $\boldsymbol{\tau}$ & $\mathbf{J}$ & $\mathbf{K}$ \\
\hline 12 & 0.0050 & 0.060 & 17.55 & $\begin{array}{l}{[-4054.16 ; 215.77 ; 2432.11 ; 3011.73 ;} \\
2388.27 ; 1011.11 ;-655.75 ;-2134.82 ; \\
-2936.34 ;-2559.53 ;-493.93 ; 3779.19]\end{array}$ \\
\hline 5 & 0.0125 & 0.0625 & 17.29 & $\begin{array}{l}{[-280.18 ; 346.82 ; 149.01 ;-208.946 ;} \\
-13.186]\end{array}$ \\
\hline 4 & 0.0250 & 0.100 & 17.13 & {$[-52.7415 ; 97.7622 ;-40.3243 ;-7.9315]$} \\
\hline
\end{tabular}

The speed deviation response corresponding to the cases shown in Table 2, is given in Figure 5.

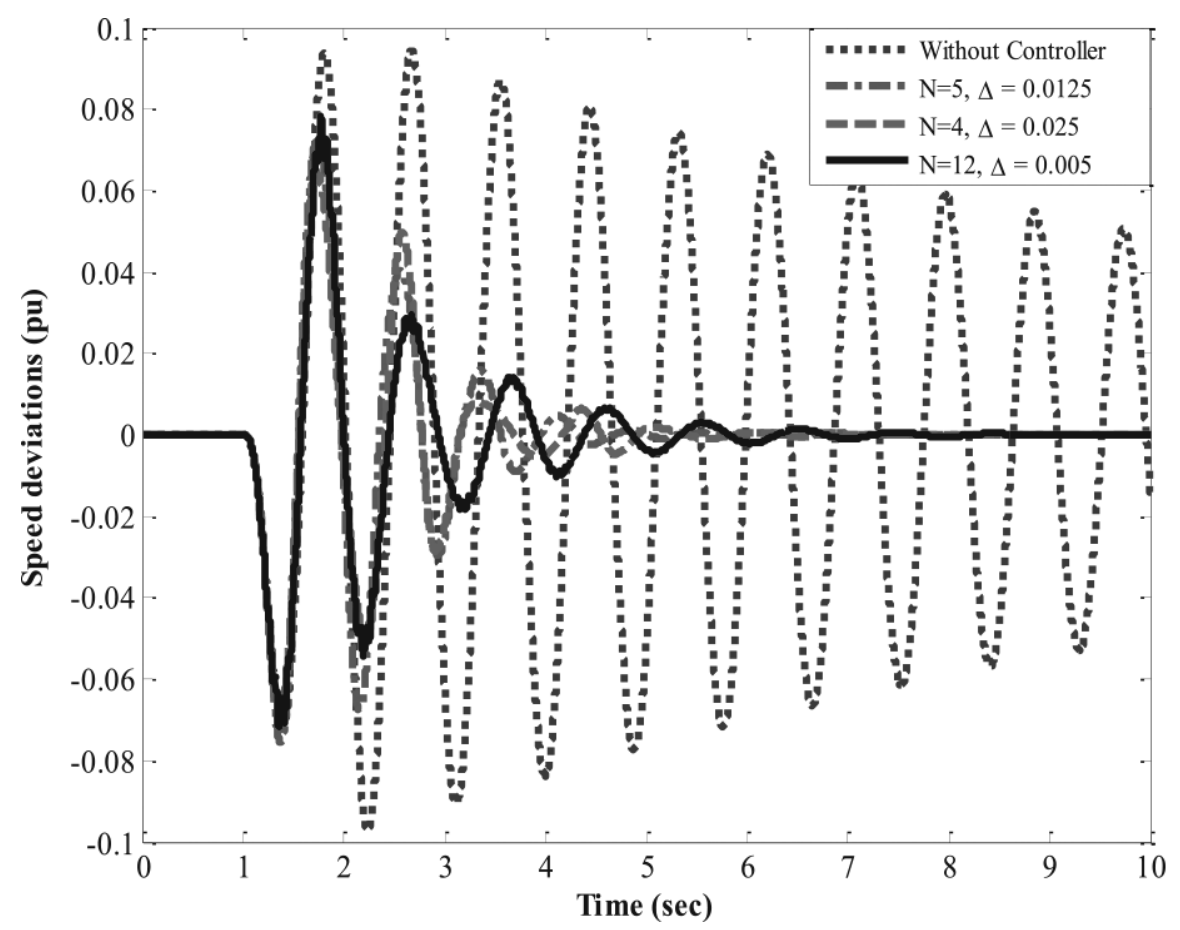

Figure 5. Time domain response corresponding to the cases mentioned in Table 2

Table 3. Optimum values of continuous mode PSS

\begin{tabular}{|c|c|c|c|c|c|}
\hline Gen. No. & Ki & T1 & T2 & T3 & T4 \\
\hline 1 & 23.98 & 0.03 & 0.02 & 2.30 & 3.76 \\
\hline 2 & 24.08 & 0.03 & 0.01 & 1.84 & 3.18 \\
\hline 3 & 19.02 & 0.03 & 0.01 & 2.60 & 4.03 \\
\hline 4 & 18.81 & 0.02 & 0.02 & 2.15 & 3.48 \\
\hline
\end{tabular}




\section{EIGEN VALUE \& SPECTRAL RADIUS ANALYSIS}

The discrete poles are transformed into corresponding continuous one, for evaluating the damping factor of complete SMIB system. Using equations (14), discrete eigen values are calculated and using equation (15) \& (16), continuous mode eigen-values are calculated analogous to discrete ones.

\section{CONCLUSION}

A POF based DPSS has proposed for given test power system, considering different sets of $\Delta$ and $\tau$. At given operating point, the optimal performance has been attainted when $\Delta$ and $\tau$ are $0.025 \mathrm{sec}$ and $0.1 \mathrm{sec}$ respectively. The corresponding optimal $\mathrm{K}$ is derived using PSO technique. In addition to time domain analysis, the modal analysis is also performed to validate the efficacy of proposed DPSS. The POF based DPSS also gives better performance as compared to classical continuous mode PSS.

Further, an attempt is also made to recommend the range of optimal sampling rates, for the given desired values of objective function $\mathrm{J}$ and the same is mentioned in Table 3.

Table 3. Range of optimal sampling rates

\begin{tabular}{|c|c|}
\hline \multicolumn{2}{|c|}{ For $\mathbf{J}=\mathbf{5 0}$} \\
\hline $\boldsymbol{\Delta}(\mathbf{s e c})$ & Possible $\boldsymbol{\tau}$ in sec \\
\hline 0.0045 & 0.045 and 0.055 \\
\hline 0.0135 & 0.06 and 0.0630 \\
\hline 0.035 & All values up to 0.215 \\
\hline
\end{tabular}

\section{REFERENCES}

Kundur, P., Klein, M., Rogers, G.J., Zywno, MS. 1989. Application of power system stabilizers for $\quad$ enhancement of overall system stability. IEEE Transactions on Power Systems. 4(2): 614-626.

Klein, M., Rogers, G. J., and Kundur, P. 1991. A fundamental study on inter area oscillation in power systems. IEEE Trans. on Power Systems. 6(3): 914-921.

Bhattacharya, K., Kothari, M. L., Nanda, J., 1995. Design of Discrete mode variable structure power system stabilizers. Electric Power and Energy Systems. 17(6): 399-406.

Park, T. M., Kim., W., 1996. Discrete time adaptive sliding mode power system stabilizer with only inputloutput measure ments. Electric Power and Energy Systems. 18(8): 509-517.

Kothari, M. L., Nanda, J., and Bhattacharya, K., 1993. Discrete mode power system stabilizers. IEE Proceedings of Generation, Transmission and Distribution. 140(6): 523 - 531.

Lee, D.C., Beaulieu, R.E., and Service, J.R.R., 1981. A power system stabilizer using speed and electrical power inputs: design and field experience. IEEE Trans., PAS-100: 1-8.

Rao, PS., Sen, I., 2000. Robust pole placement stabilizer design using linear matrix inequalities. IEEE Trans. on Power Systems, 15(1): 313-319.

Gupta, R., Bandyopadhyay, B. and Kulkarni, A.M. 2005. Design of power system stabiliser for multi-machine system using robust periodic output feedback controller. IEE Proceedings- Generation, Transmission and Distribution, 152(1): 
Chammas, A.B., and Leondes, C.T., 1979. Pole assignment by piecewise constant output feedback. Int. J. Control. 29:31-38.

Priya, P. S. L., and Bandyopadhyay, B., 2012. Periodic Output Feedback based Discrete-Time Sliding Mode Control for Multivariable Systems. 2012 IEEE International Conference on Industrial Technology (ICIT): 893-898.

Bandyopadhyay, B. and Janardhanan, S., 2005. Discrete-time Sliding Mode Control: A Multi-rate Output Feedback Approach. Lecture Notes in Control and Information Sciences, Berlin: Springer-Veriag .323.

Patre, B.M. and Bandyopadhyay, B., 1998. Periodic output feedback control for two-time-scale discrete systems. TENCON '98. 1998 IEEE Region 10 International Conference on Global Connectivity in Energy, Computer, Communication and Control. 1: 174-177.

Werner H. and Furuta K., 1995. Simultaneous stabilization based on Output measurement. Kybernetika. 31(4): 395-411.

Gupta, R., Bandyopadhyay, B. and Kulkarni, A.M. 2003. Design of power system stabiliser for single-machine system using robust periodic output feedback controller. IEE Proceedings- Generation, Transmission and Distribution. 150(2): 211-216.

Bhadu, M., Senroy, N., and Janardhanan, S., 2016. Discrete Wide Area Power System Damping Controller using Periodic Output Feedback. Electric Power Components and Systems Journal, 44(17): 1892-1903.

Kennedy, J., and Eberhart, R., 1995. Particle swarm optimization. IEEE International Conference Proceedings on Neural Networks. 4: 1942-1948.

Abido, M. A., 2002. Optimal design of power-system stabilizers using particle swarm optimization. IEEE Trans. on Energy Conversion. 17(3): 406-413.

Abd-Elazim, S.M., Ali E.S., 2013. A hybrid Particle Swarm Optimization and Bacterial Foraging for optimal Power System Stabilizers design. Electric Power and Energy Systems. 46: 334-341.

Eslami, M., Shareef, H., Mohamed, A., and Khajehzadeh, M., 2012. An efficient particle swarm optimization technique with chaotic sequence for optimal tuning and placement of PSS in power systems. Electric Power and Energy Systems. 43: 1467-1478.

Mostafa, H.E., El-Sharkawy, M.A., Emary, A.A., and Yassin, K., 2012. Design and allocation of power system stabilizers using the particle swarm optimization technique for an interconnected power system. Electric Power and Energy Systems. 34: 57-65.

Anderson P. M. and Fouad A., 1977. Power System control and stability. Iowa State Univ. Press.

DeMello, F.P., and Concordia, C., 1969. Concepts of Synchronous Machine Stability as Affected by Excitation Control. IEEE Trans. on Power Apparatus and Systems. 88(4): 316-329.

Sauer P. W. and Pai M. A., 1998. Power System Dynamics and Stability. Prentice Hall.

Heffron W.G. and Phillips R. A., 1952. Effect of a Modern Amplidyne Voltage Regulator on Underexcited Operation of Large Turbine Generators [includes discussion]. Power Apparatus and Systems, Part III. Trans. of the American Institute of Electrical Engineers. 71(1): 692-697.

Kundur, P., 1994. Power System Stability and Control. McGraw-Hill.1994.

Son, K. M., and Park, J.K., 2000. On the robust LQG control of TCSC for Damping Power System Oscillations. IEEE Trans. on Power Systems. 15(4): 1306-1312.

Glover, K., 1984. All optimal Hankel norm approximations of linear multivariable systems and their L $\infty$ error bounds. International journal of control. 39(6): 1115-1193. 
“Matlab Users Guide,” MathWorks, Natick, MA, 2010.

Bhadu, M., Senroy N., Kar, I. N. et. al, 2016. Robust linear quadratic Gaussian-based discrete mode wide area power system damping controller", IET Generation Transmission \& Distribution,10(6):1470-1478.

Bhadu, M., and Senroy, N., 2014. Real time simulation of a robust LQG based wide area damping controller in power system. IEEE PES Innovative Smart Grid Technologies, Europe. 